\title{
Pricing of Reverse Mortgage on Forward House Sale
}

\author{
Tobias Baer, Isil Erol, Kanak Patel*, Ricardo Pereira and Sung-Jin Yoo
}

\section{Introduction}

In Japan, Korea, the USA, Canada, the UK, Australia, and France, a variety of reverse mortgages have been introduced over the past two decades. In the early $1990 \mathrm{~s}$, reverse mortgages started to gain popularity in the USA after the Federal Housing Administration began insuring the mortgages for repayment to lenders. Existing reverse mortgage products, such as the House Equity Conversion Mortgage (HECM) of the US Department of Housing and Urban Development, and the reverse mortgages introduced in Korea in 1995, are structured as simple non-recourse loan contracts.

This paper aims to analyse the risks involved in reverse mortgage on a forward sale of house by elderly homeowner. We provide a practical solution to institutions planning to issue such reverse mortgages. We propose the formation of Senior Citizens Housing Trust for retired homeowners who wish to sell their homes forward in order to raise cash through reverse mortgages. Under a forward house sale agreement, the homeowner enters into a contract to transfer the property to $\mathrm{SCH}$ at the time of their death in exchange for reverse mortgage on the property. The SCH Trust reverse annuity mortgage enables homeowner to draw down the full home equity over their remaining life.

The Home Equity Conversion Mortgage (HECM) is the oldest (since 1989) and most popular reverse mortgage product in the US. It is insured by the Federal Government through the Federal Housing Administration (FHA), a division of the U.S. Department of Housing and Urban Development. An FHA-insurance enables HECMs to carry a low interest rate and yield more to borrowers. The amount of money the borrower receives from a HECM depends on age, appraised house value and current interest rate, similar to other reverse mortgage products, plus the location of the property, which is unique in HECM. Case and Schnare (1994) evaluated the HECM reverse mortgage programme, suggesting strong demand for reverse mortgage among "house-rich, cash-poor" elderly homeowners.
In March 2006, Citibank launched the first European reverse mortgage securitization transaction, primarily targeted at UK long-dated fixed-rate investors. The originator is Norwich Union Equity Release Ltd, a special-purpose entity Equity Release Funding (No.1) PLC. This securitization is a new funding strategy to refinance mortgage equity release products. It is a flexible financing tool that allows for cost-effective refinancing. The demand for this type of product is expected to increase over time as the population of older people grows. This is the first time that Standard \& Poor's Structured Finance ratings group in Europe has assigned preliminary ratings to a reverse mortgage transaction. It has been necessary to adopt a different approach to its traditional RMBS analysis. Monte Carlo approach is used to profile and assess the requirement for credit enhancement and liquidity.

The layout of the rest of this paper is as follows: Section 2 outlines the institutional framework for the formation of Senior Citizen Housing Trust to enable retired homeowners to sell their houses forward in order to enhance their retirement income. Section 3 explains the calculation of the break-even annuity. Section 4 describes the data used in Monte Carlo Simulations and presents key simulation results. Section 5 presents some concluding remarks.

\section{Capitalization of the $\mathrm{SCH}$ Trust}

In the proposed structure, the Senior Citizen Housing Trust would hold risky assets (namely houses or, more specifically, claims on the sale price of houses the timing and value of which both are uncertain) and also would face uncertain liabilities (namely the annuity payments to the senior citizens, the length and hence total present value of which are uncertain). In order to absorb such losses at least temporarily - if overall expectations are correct, shortfalls in some periods should be offset by surpluses in other periods - the SCH Trust needs to be capitalized by equity to serve as a buffer for such losses. There appear to be three possible solutions for capitalizing the SCH Trust:

(i) $100 \%$ equity financing of the Trust's cash needs by equity investors; 
(ii) Provision of an amount of equity by equity investors that is sufficient for the probability of default of the Trust to be within the desired level of security (e.g., for the Trust to have a risk level that is comparable to borrowers that are rated AAA by Standard \& Poor's, it would need to have a probability of default not exceeding $0.01 \%$; a risk level comparable to a $\mathrm{BBB}$ rating would be roughly a $1 \%$ chance of the equity not being sufficient to absorb temporary losses);

(iii) Provision of an amount of equity by the homeowners that is sufficient for the probability of default of the Trust to be within the desired level of security.

\section{Reverse Annuity Mortgage on Forward House Sale}

A reverse annuity mortgage on forward house sale contract is a complex product because it entails three fundamental risks. First of all, there is the longevity risk of the homeowner. The uncertainty over the death of the homeowner affects the value of the reverse mortgage in two ways: it determines the number of periods the annuity has to be paid (and hence the total amount being paid out) and for which period the SCH Trust incurs financing cost for any payments made to the homeowner until the Trust can sell the property after the homeowner's death. Second, there is the price risk when the homeowner dies. Third, there is a substantial amount of interest rate risk involved. The $\mathrm{SCH}$ Trust neither knows at which interest rate it will be able to refinance future annuity payments to the homeowner, nor the time when the proceeds from the sale of the house will come in. This translates into both a house risk and a financing risk.

Because an analytical approach cannot capture the combination of these three risk factors, Monte Carlo simulation is employed to price the risk of $\mathrm{SCH}$ Trust reverse mortgage. The simulations are based on the UK house price, interest rate, and mortality tables. While the UK data is be used for this demonstration, the approach is universally applicable.

A simplest way for the SCH Trust to manage the refinancing of a reverse mortgage would be to refinance it at the short term interest rate; in this case, however, any increase in interest rates would increase the lender's funding cost, while any drop in interest rates would decrease funding cost. The pricing model is based on this refinancing approach in order to capture the full interest rate risk.

\section{The Break-even Price of Reverse Mortgage}

The break-even price of SCH Trust reverse mortgage is calculated such that the present value of the mortgaged property equal the present value of annuity payments made to the homeowner plus the present value of interest expenses; the "price" of the reverse mortgage therefore is the break-even present value of annuity amount. The break-even annuity amount reflects the longevity risk as well as the uncertainty of future interest rate and house price risk. This present value of annuity amount can be obtained by estimating present value of the property at the time of death of the homeowner and the index of the present value of annuity and the funding expense for a sufficiently large random sample of homeowners.

In order to calculate the index of the annuity and funding expenses for the SCH Trust, the future paths of the interest rate is simulated using Monte Carlo simulation. Each simulation is performed for the period from 2006 to the mortality year. Future interest rate is estimated based on the basic assumption that the interest rate evolves according to a mean-reverting square root diffusion process. Due to the long life of the reverse mortgage, a key requirement of the interest rate simulation is for the interest rate to revert to its long term mean, the Cox, Ingersoll and Ross model (Cox et al, 1985), based on the stochastic process

$$
d r=\kappa\left[\theta-r_{t}\right] d t+\sigma \sqrt{r_{t}} d W
$$

(1)

where $\kappa$ represents the speed of adjustment at which $r$ returns to the long term mean and $\theta$ the long term mean value of interest rates. $\sigma$ is the instantaneous standard deviation of the interest rate disturbance, denoting the volatility of interest rates, $\mathrm{dW}$ is the standardised Wiener process.

The future path of house price is assumed to follow the same structure as the interest rate model. The growth rate of house prices is forecasted using a mean-reverting square root diffusion process. The growth rate is assumed to revert with speed $\kappa$ to its long-term mean $\theta$ and experience normal-distributed random disturbances with a standard deviation of $\sigma$ that are scaled by the square root of the previous period's growth rate:

(2)

$$
d g=\kappa\left[\theta-g_{t}\right] d t+\sigma \sqrt{g_{t}} d W
$$

Mortality year is the point of time when the reverse mortgager dies after making a reverse mortgage contract. ${ }^{1}$ Once the mortgager's gender and entry age at time of the mortgage

\footnotetext{
${ }^{1}$ For simplification the calculation of the mortality year, people are assumed to die only at the beginning of the year
} 
contract are decided, a conditional probability of death each year after the reverse mortgage contract is calculated. The mortality year is simulated by drawing a random variable that is equally distributed between 0 and 1 . This random variable is mapped into the mortality table using cumulative probabilities of the death.

The three key input variables, randomly selected mortality year, stochastic interest rate and house price growth rate until the mortality year, are used to calculate an index of the annuity and funding expenses for the given reverse mortgage and the expected house price in the mortality year. For example, if the $\mathrm{SCH}$ Trust makes 12 annuity payments until the mortgager dies, the annuity index would be 12 before interest expense. Assuming a constant 5 percent interest rate, the annuity index would be 15.91713 , reflecting the cost of funding incurred by the bank, which in this example would be equal to 15.91713 annuity.

The simulation calculates the annuity of the reverse mortgage by dividing average of the expected house price by average of the annuity index, which makes the total expected profit over the entire portfolio zero. Then this annuity is converted to a monthly payment, dividing the calculated annuity by 12 .

$\sum_{t} H P_{i}-\sum_{t}$ Annuity $\times$ Ann $\cdot$ Index $_{i}=0$

$$
\therefore \text { Annuity }=\frac{\sum H P_{i}}{\sum A n n \cdot I n d e x_{i}}
$$

\section{Data and Empirical Results}

The original interim life tables of the UK are obtained from Government Actuary Department, which is based on population data from 2002 to 2004 . The UK interest rate data since 1694 is obtained from the Bank of England. The UK house price data since 1946 is obtained from the Office of Deputy Prime Minister. Similar to the interest rate model, the long term mean $\theta$ and the speed $\kappa$ at which $r$ returns to the long term average in the mean-reverting house price model is derived by regressing the change in the house price growth rate on the previous period's growth rate.

\subsection{The Base Case}

In the base case "price" of the reverse mortgage, that is the annuity offered by $\mathrm{SCH}$, three basic risk drivers are specified: the current age and gender of the mortgager (as both factors determine the person's life expectancy or longevity risk) and the current value property. We base all calculations on a house with a current value of $£ 100,000$.

As an example, let us consider a 65 year old female. After 2,000 scenarios, the Monte-Carlo simulation puts her expected life expectancy (i.e., the average remaining life time in the 2,000 scenarios) at 18.79 years. The average expected housing price at the time of death is $£ 445,954$. The average of the annuity index at the time of death is 35.0598 ; this implies that on average, the annuities paid by the $\mathrm{SCH}$ Trust and the cost of funding incurred until the sale of the house accumulate to 35.0598 times the annuity. The break-even annuity therefore is $£ 12,720$ per year ( $£ 445,954$ divided by 35.0598). This means that if the SCH Trust agrees to pay to a portfolio of 65 year old female mortgagers an annuity of $£ 12,720$ each for every $£ 100,000$ in original house value, it expects that the sum of the annuities paid and funding costs incurred will exactly equal the total proceeds from selling the houses.

For a 65 year old female the life expectancy is 18.79 years, while for a male of the same age it is just 15.73 years. As a result, a 65 year old female is offered $£ 12,720$, whereas a male mortgager of the same age is offered $£ 12,980$.

\subsection{Interest Rate Scenarios}

As discussed earlier, the long-term average interest rate in the United Kingdom has been fairly stable around $4.73 \%$ for the past 300 years. The historical standard deviation of interest rates varies substantially, however, depending on the period of which it is measured. For the base case, the standard deviation is measured over the past 10 years and amounted to 0.0105 . If measured over the past 300 years, by contrast, it would be increased to 0.0209. Figure 1 shows the break-even annuity for 65,75 and 85 year old females both for the base case and the higher interest rate volatility assumption.

\section{Figure 1 Changes in reverse mortgage payments by high interest rate volatility}

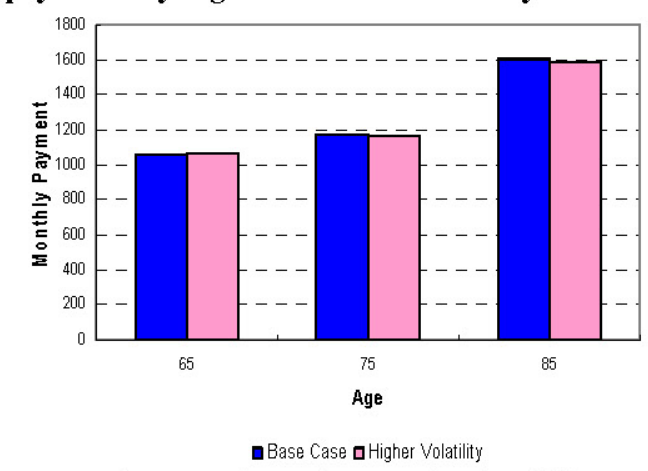

As can be seen from the graph, the difference between two cases with the base volatility $(0.0105)$ and the high volatility $(0.0209)$ of 
each age actually is minimal. One reason for the negligible difference is the fact that the SCH Trust is assumed to be risk-neutral; if one measured the short-fall risk and included the cost of the economic capital required to absorb any short-fall with a given probability (i.e., $99 \%$ ), the cost of that economic capital would increase with the interest rate volatility, translating into lower break-even annuity amounts.

On the other hand, a sustained change in the long-term average interest rate would have a profound impact on the pricing of reverse mortgaged. Figure 2 shows the break-even annuity for the base case and two alternative scenarios where the long-term average interest rate is assumed to be one percentage point below and above the historical mean, respectively. It displays that each age group receives a larger amount of monthly payment as the long-term average of interest rate decrease, and the sensitivity of the long-term average of interest rate diminishes as the age of the mortgager grows.

Figure 2 Annuities by changing the long-term averages of interest rate

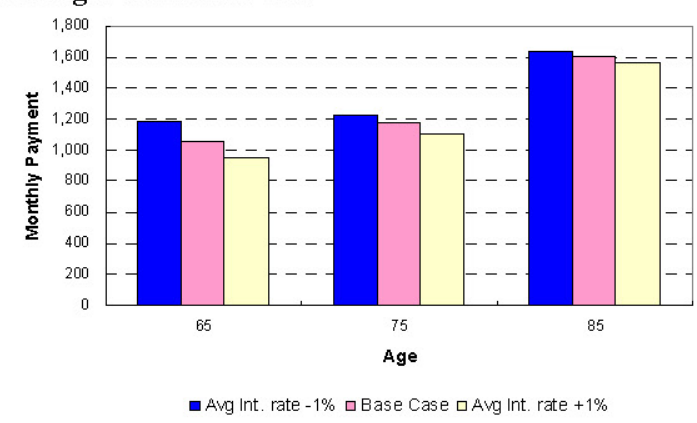

\subsection{House Price Appreciation Scenarios}

The UK housing market has enjoyed a long period of price appreciation in excess of the growth in GDP. In particular, during the past 15 years the GDP growth has dropped significantly from over $10 \%$ to just $5-6 \%$ per year, while UK housing prices have continued to grow in average around $10 \%$ per year. The primary concern in pricing a reverse mortgage therefore would be how UK housing prices will develop in the future.

Figure 3 show the break-even annuity for 65 , 75 and 85 year old female mortgagers for two scenarios: the base case (assuming long-term annual growth in UK housing prices of $7.1186 \%$ ) and an alternative case where house prices grow with the same annual growth rate as GDP has grown over the past 10 years (i.e., $5.5 \%$ per year). One key driver for the growth in house prices historically has been the location. Since 1969, house prices grew even faster than the long-term average - from 9.3\% annual growth in Scotland to $10.5 \%$ annual growth in England. The comparison of these growth rates with both the long-term growth rate of housing prices in the UK and GDP growth suggests that these growth rates are not sustainable, and therefore should not be used for the simulation.

Figure 3 Annuities by changing the long-term growth rate of the house price

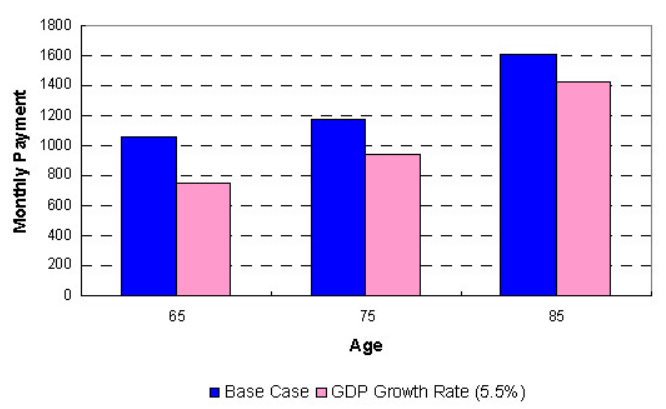

\section{Conclusion}

In this paper a Monte Carlo simulation based approach is used to price the three fundamental risks entailed by a reverse annuity mortgage contract with full transfer of the economic ownership of the mortgaged house to $\mathrm{SCH}$ Trust. To our knowledge, the existing research has not proposed any comprehensive solution to pricing reverse mortgage with interest rate, house price and longevity risk factors. The application of the concept to a sample of UK data has demonstrated not only that the model can be implemented quite easily, but also that it yields stable results for a range of scenarios for the key input parameters.

\section{References}

Case, B. and Schnare, A.B., 1994, "Preliminary Evaluation of the HECM Reverse Mortgage Program," Joumal of the American Real Estate and Urban Economics Association, 22(2): 301-346.

Chinloy, P. T. and Megbolugbe, I. F.,1994, "Contracting and Crossover Risk," Joumal of the American Real Estate and Urban Economics Association, 22(2):367-386.

Cox, J., Ingersoll, J. and Ross S., 1985, "A Theory of the Term Structure of Interest Rates," Econometrica, 53(2): 385-407.

Syzmanoki, E. J. Jr., 1994, "Risk and the Home Equity Conversion Mortgage, "Joumal of the American Real Estate and Urban Economics Association, 22(2): 347-366. 